\title{
Comparative Evaluation Method for Fire Safety Design of Large Storage Spaces
}

\author{
ZHENKUN WU ${ }^{1,2}$, HAIHANG LI ${ }^{1}$, YAPING HE ${ }^{3}$, DECHUANG ZHOU ${ }^{1}$, JIAN WANG ${ }^{1}$ \\ ${ }^{1}$ State Key Laboratory of Fire Science, University of Science and Technology of China, Jinzhai \\ Road 96, Hefei, Anhui, China \\ ${ }^{2}$ Anhui General Fire Brigade, Hefei 230031, Anhui, China \\ ${ }^{3}$ School of Computing, Engineering and Mathematics, University of Western Sydney, Kingswood \\ Campus, Penrith, New South Wales, Australia
}

\begin{abstract}
The design philosophy "the safety level of a performance-based designed building should not be lower than that of a prescriptive" with objectives of property protection and life safety was implemented in this paper. Three countervailing solutions were adopted to reduce fire risk in the $11664 \mathrm{~m}^{2}$ case storage. Besides, a virtual prescriptive storage with identical length-width ratio and similar ventilation conditions as the performance-based was designed for comparison. After designing the fire development event tree and simulating six fire scenarios using FDS, the two objectives were achieved as fire severity and risk of property loss of the performance-based design storage were found to be no higher than those of the prescriptive design and ASETs were greater than RSETs for all fire scenarios.
\end{abstract}

KEYWORDS: comparative evaluation, performance-based design, large storage spaces

\section{INTRODUCTION}

Performance-based building codes and corresponding fire engineering design methods [1,2] have been adopted in many countries in order to better meet the needs for designing modern buildings with the desired functionality, aesthetics and cost-effective safety measures. When designing a new building, the highest priority should be given to the safety of building occupants especially for densely populated places [3]. The performance requirements of most building codes are primarily concerned with life safety of building occupants. But for sparsely populated buildings, such as storage, this requirement may no longer be adequate and reducing property losses becomes one of the design objectives.

He and Grubits [4] pointed out that extra measures for reinforcing fire protection may counteract increased fire risk caused by larger building areas. This situation is acceptable if the fire protection rating is no lower than the fire severity, that is to say, the safety margin is greater than zero. This method can be used to assess the life safety of building occupants. But according to the regulations [5] in China, fire protection rating is often defined as Level Two while fire hazard is often defined as Class C. The fire protection rating and fire hazard cannot be directly used for comparison because their definitions and units are completely different [6].

"Build a safe building" may become the design philosophy without specifying detailed rules to achieve this goal. To be specific, buildings can be designed flexibly as long as the performance requirements of the building codes are satisfied. One of the challenges of performance-based design is to demonstrate quantitatively that the performance requirements of the building codes are indeed satisfied. In addition to this challenge, one also needs to demonstrate that all design objectives are met particularly when property protection is part of the objectives. Quantifiable performance requirements are difficult to find in building codes. Fire safety engineers often resort to the equivalence approach in which the prescriptive provisions or deemed-to-satisfy provisions are used as benchmarks [4]. This approach, also known as the equivalence approach, is based on the design philosophy that "the safety level of a performance-based design building should not be lower than that of a prescriptive design".

\section{OBJECTIVES AND OVERVIEW OF METHODOLOGY}

In the performance-based approach, the fire safety designer is free to choose how to comply with the design criteria, as long as the solutions ensure the same protection level as the prescriptive design. Such solutions are typically verified and supported by engineering assessment showing that the risk of a performance- 
based design is lower than that associated with the prescriptive code complying design. The main objective of this paper is to demonstrate through a case study the implementation of the design philosophy that "the safety level of a performance-based building design should not be lower than that of prescriptive code complying design". The design philosophy can be addressed from the perspective of either life safety or property protection or both. In terms of risk or expected loss, the design philosophy can be stated as "the risk to life and the expected fire loss of a performance-based designed building should not be greater than that of prescriptive design".

The particular example in which this philosophy is implemented is the design of an oversized storage building. In this study the design objective is to achieve adequate protection for both life and property. The assessment methods to address the two objectives can be detailed as follows.

\section{Life Safety}

For the evaluation of life safety, the widely used timeline approach is adopted. The assessment criterion is that the available safe egress time (ASET) is greater than the required safe egress time (RSET) [7]:

$$
\text { ASET > RSET }
$$

The ASET can be determined using computational simulation techniques and tenability criteria $[1,8]$.

\section{Property Protection}

The property protection objective is to minimize the potential loss of property. The assessment of property employs a risk based approach. During the lifetime of a building, the potential fire hazards may be present in different forms. In a given fire incident, there may be many possible sequences of events. Each sequence of events constitutes a scenario. The overall fire risk of property loss in a scenario can be quantitatively expressed as the product of probability of a fire scenario and its consequence [8]:

$R_{j}=F_{j} \times C_{j}$

where

$j=$ fire scenario index;

$R_{j}=$ risk of fire scenario $j$ in terms of property loss;

$F_{j}=$ probability of fire scenario $j$;

$C_{j}=$ consequence of fire scenario $j$.

The overall expected property loss, or fire loss, $R$, is evaluated from

$$
R=\sum_{j=1}^{N} R_{j}
$$

In terms of the expected fire loss, design philosophy can be expressed as

$$
R_{P B D} \leq R_{\mathrm{Pr} e}
$$

where subscript $P B D$ represents performance-based designed storage, subscript Pr $e$ represents prescriptive designed storage. $F_{j}$ can be determined by event tree analysis $[9,10]$ and $C_{j}$ is the property loss of scenario $j$. For simplicity, the costs of protection investment and operation are not considered here. 


\section{APPLICATION OF THE METHODOLOGY}

The application of the above outlined methodology is demonstrated through a case study in the following sections.

\section{Project Overview}

The building selected for case study is an outbound storage of a new factory in China. A schematic plan of the one storey storage building is shown in Fig. 1, where it can be seen that the total floor area is $11664 \mathrm{~m}^{2}$. This storage is divided into 24 smoke bays each $27 \mathrm{~m}$ long and $18 \mathrm{~m}$ wide. Every smoke bay is equipped with a fan of $8.3 \mathrm{~m}^{3} / \mathrm{s}$ exhaust capacity. The smoke exhaust system is designed to activate after sprinkler activation by linkages to the sprinkler system and the detection system. The building height is $10 \mathrm{~m}$ and the stacking height of goods is $6 \mathrm{~m}$. According to the fire code of China [5], the classification of fire hazard of this storage is Class $\mathrm{C}$ and the fire resistance rating should be Level Two, and the allowable maximum fire partition area is $3000 \mathrm{~m}^{2}$ after an automatic sprinkler system has been installed as required. However, this storage building was intended to be designed as a single fire partition due to the requirement of logistics supply efficiency. So now the contradiction of the building area appears between the requirement of the building function and the restrictions of the fire code.

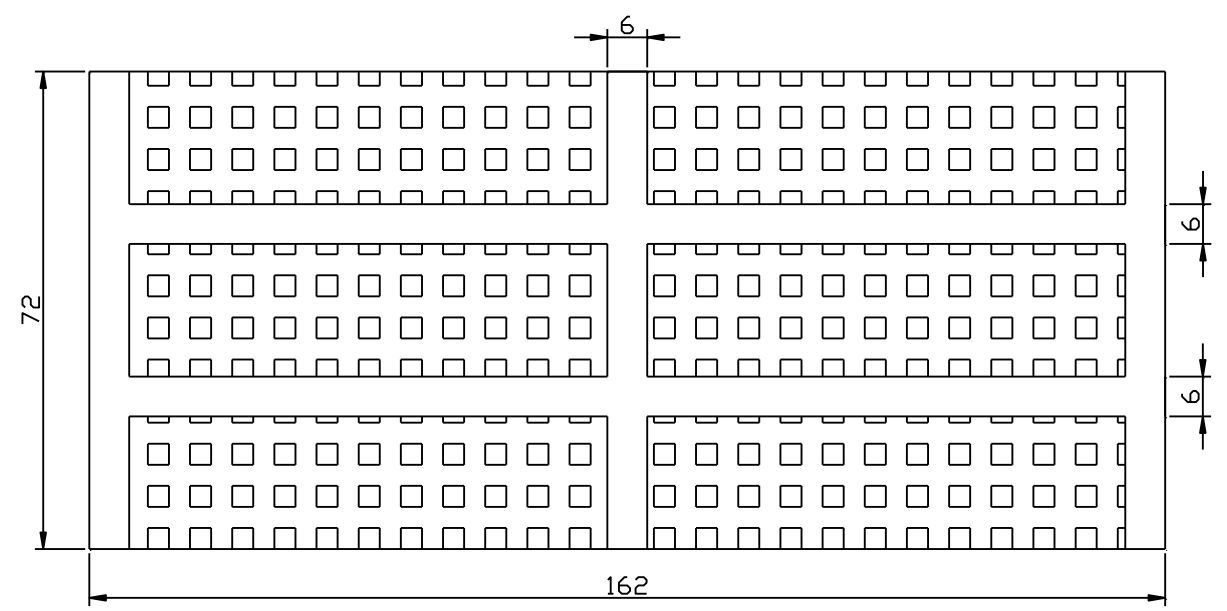

Fig. 1. The geometry of the original performance-based design storage. Square filled areas are refrigerator stackings while blank areas are passages. Measurements are given in meters.

\section{Countervailing Solutions}

Several solutions can be adopted to countervail the increased fire risk caused by the enlarged fire partition area. Early suppression fast response sprinkler system was introduced to control the development of the initial fire; fire separation zones were set between the refrigerator stackings to prevent fire spread from one stacking to another; fire retardant coating was used to strengthen the fireproof property of the steel structures of the storage building. The details of the above solutions are as follows:

- The parameters of early suppression fast response sprinkler (ESFR) for this storage were selected on basis of building height and fire risk. The sprinklers have a $\mathrm{K}$ factor of $360 \mathrm{~L} / \mathrm{min}^{\circ}$ bar ${ }^{1 / 2}$ and have an activation temperature of $74{ }^{\circ} \mathrm{C}$. They have an RTI-value of $36 \sqrt{\mathrm{ms}}$ and the outlet pressure of the sprinklers is $0.45 \mathrm{MPa}$. Twelve sprinklers were designed to act together with a duration time of one hour. The corresponding total water flow rate is $152 \mathrm{~L} / \mathrm{s}$. The sprinklers were mounted at locations 0.5 $\mathrm{m}$ below the pitched roof.

- Fire separation zone in buildings is a empty area of a certain width and combustibles are strictly prohibited within this area. So fire separation between the refrigerator stackings is proposed to isolate combustibles without sacrificing building integrity. In an earlier study [11] it has been determined that the 6 meters wide transport passages can be set as fire separation zones to prevent fire spread between stackings if the sprinkler system is effective. In case of the sprinkler system failure, the fire separation 
zone transport passages should be broadened to 11 meters to prevent fire spread. The width of $11 \mathrm{~m}$ is adopted in the alternative solution. The design sketch of broadened fire separation zones is shown in Fig. 2. Although the increased width of transport passages reduces the storage area, it, on the other hand, brings the benefit of easier access and more rapid turnover in a busy warehouse.

- Coat protection level of steel structures of this storage meets the requirements of Type 332 building in NFPA 5000-2006 [12]. Specifically, the fire-resistance time is as follows: walls $\geqslant 3 \mathrm{hr}$, columns $\geqslant 2$ $\mathrm{hr}$, beams $\geqslant 2 \mathrm{hr}$, and purlins $\geqslant 2 \mathrm{hr}$.

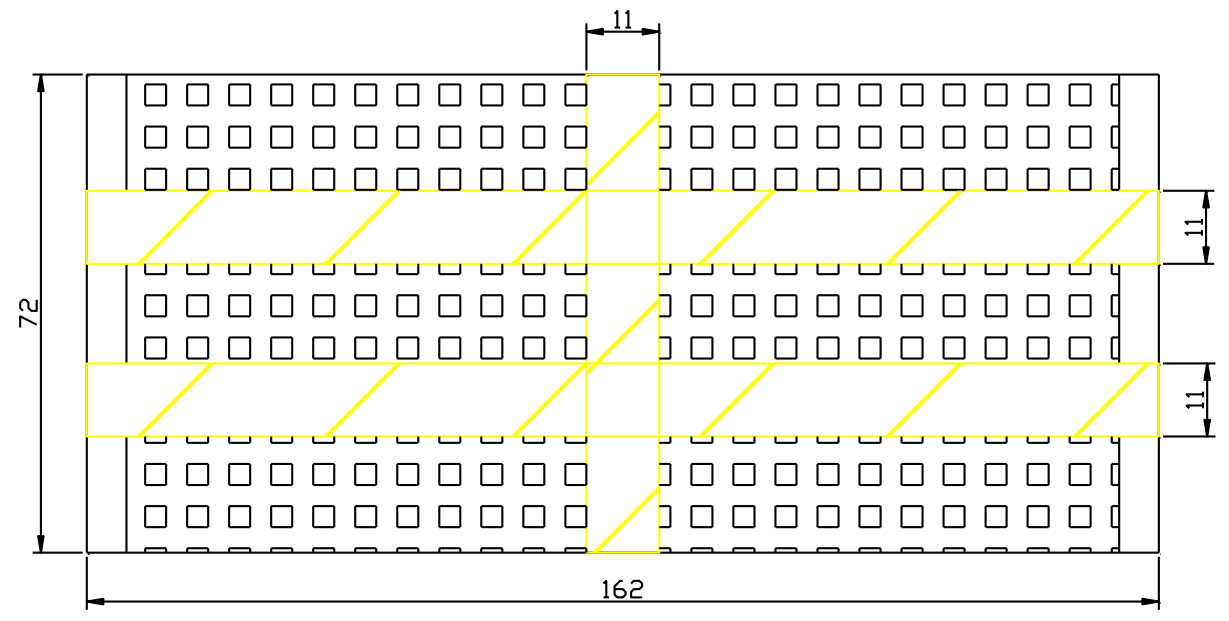

Fig. 2. Modified alternative solution with broadened fire separation zones shown in white bias. Measurements are given in meters.

\section{Virtual Prescriptive Designed Storage}

A virtual storage satisfying the prescriptive fire regulation is used for equivalence analysis. The virtual prescriptive design storage consists of 6 smoke bays with each bay the same as in performance-based storage. So the length-width ratios of these two storages are identical and the ventilation conditions are similar. The building area of the prescriptive design storage covers $2916 \mathrm{~m}^{2}$. Standard sprinklers were selected and the mechanical smoke exhaust volume is $48.6 \mathrm{~m}^{3} / \mathrm{s}$. The mechanical smoke exhaust volume for the performance-based storage is $194.4 \mathrm{~m}^{3} / \mathrm{s}$ so that the volume of a unit area is the same as the prescriptive storage. Two stackings are arranged in the prescriptive storage with a central passage dividing them, Fig. 3.

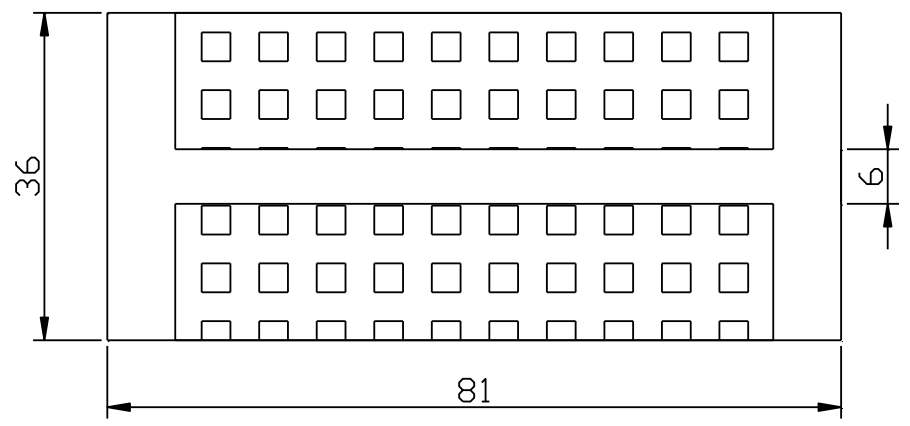

Fig. 3.Virtual prescriptive design storage. Square filled areas are refrigerator stackings while blank areas are passages. Measurements are given in meters. 


\section{Tenability Criteria}

In [1] the following evacuation safety criteria are given. Based on these, the time when critical conditions appear can be found. They are:

- Gas temperature: the temperature below the safety height $(2.6 \mathrm{~m})$ should be lower than $60{ }^{\circ} \mathrm{C}$ for safe evacuation.

- $\quad \mathrm{CO}$ and $\mathrm{CO}_{2}$ concentration: the concentration of $\mathrm{CO}$ and $\mathrm{CO}_{2}$ below the safety height $(2.6 \mathrm{~m})$ should be lower than $1400 \mathrm{ppm}$ and $6 \%$ respectively.

- Visibility: the visibility should be better than $10 \mathrm{~m}$ in this huge compartment.

\section{Property Loss Criteria}

Fire severity is a measure of fire intensity and here it is represented by the smoke layer height, smoke layer temperature, and radiation intensity at the top of the stackings. In the assessment of the relative safety level between prescriptive and performance-based design, these parameters will be compared with the critical values first and then compared mutually. The critical values [1] of these indexes are:

- Smoke layer height: a height of $1.6 \mathrm{~m}+0.1 \mathrm{H}$ from the floor, so the critical value of this storage is 2.6 m.

- Smoke layer temperature: when the temperature of the smoke layer reaches $600{ }^{\circ} \mathrm{C}$, the combustibles in the room will ignite causing flashover.

- Radiation intensity at 6 meters high: the combustibles in this storage are classified as easily ignited goods thus the critical value of radiation heat flux is $10 \mathrm{~kW} / \mathrm{m}^{2}$.

\section{Fire Scenarios}

After hazard identification, the combustibles in this storage are refrigerators and their packages that are piled up stacking by stacking. The main igniting sources are failure of electric trailer and electric forklift as well as irregular operation. The risk analysis is carried out by quantitatively evaluating a number of fire scenarios. The evaluation calculates the probabilities and consequences for all scenarios in the event tree. Fire event tree is a logic diagram illustrating the fire development that is mainly affected by the sprinkler system, the smoke extraction system and the fire separation zone.

Table 1. Reliabilities of sprinkler and smoke extraction systems.

\begin{tabular}{|l|c|}
\hline \multicolumn{1}{|c|}{ System } & Reliability (\%) \\
\hline Sprinkler system & $89.9[13]$ \\
\hline Smoke extraction system & $97.4[14]$ \\
\hline
\end{tabular}

The reliabilities of the sprinkler and smoke extraction systems have been summarized in Table 1. It is recognized that uncertainties or variabilities exist in these data [15] and the outcomes of the assessment of each individual designs will depend on the selection of these input data. However, because of the comparative nature of the assessment methodology employed in the current study and because the impacts of these input data on the assessment outcomes of the performance-based design and the prescriptive code compliant design would be the same or similar, it was hypothesized that the dependence or the sensitivity of the final comparison to the two design assessments would be low or negligible.

For the reliability of the fire separation zone, no statistical data can be found in the literature. According to our general knowledge, jump fire and bridging can be contributing factors to the failure of a fire separation zone. The probability of a jump fire is related to the failure probability of smoke extraction system, considering that fire brands as the result of carton burning will not be exhausted in case of smoke extraction system failure. Bridging of fires between stackings can also be caused by the existence of electric trailer or forklift in the transport passages. In normal operation there is one trailer or forklift in the storage, so the space existence probability of electric equipments around the initial fire stacking can be assumed as the passage perimeter of the stacking divided by the total length of the passages (here it is 0.32 ). According to the data provided by the operating departments, electric trailer and forklift work 14 hours per day so the time existence probability of electric equipment is 0.58 . Besides, the probability of driving electric 
equipment out of the storage by the driver in case of a fire is assumed to be 0.5 . To sum up, the probability of bridging of the initial fire stacking and its adjacent stackings is $0.32 \times 0.58 \times 0.5=0.0928$.

Through the analysis and calculation above, if the smoke extraction system is effective the failure probability of fire separation zone is 0.0928 ; if the smoke extraction system is ineffective the failure probability of fire separation zone is $0.026+0.0928=0.1188$. Based on these probabilities, the event tree for a fire development in the present storage building is drawn in Fig. 4. The fire intensity of each scenario will be calculated by the Fire Dynamics Simulator 5 [16] and will be compared between the prescriptive and the performance-bas designed storages. On the other hand, the expected number of damaged refrigerators will be obtained by multiplying the probability of the specific scenario by its consequence. The total risk of property loss associated with the building is the summation of all the scenarios in the event tree.

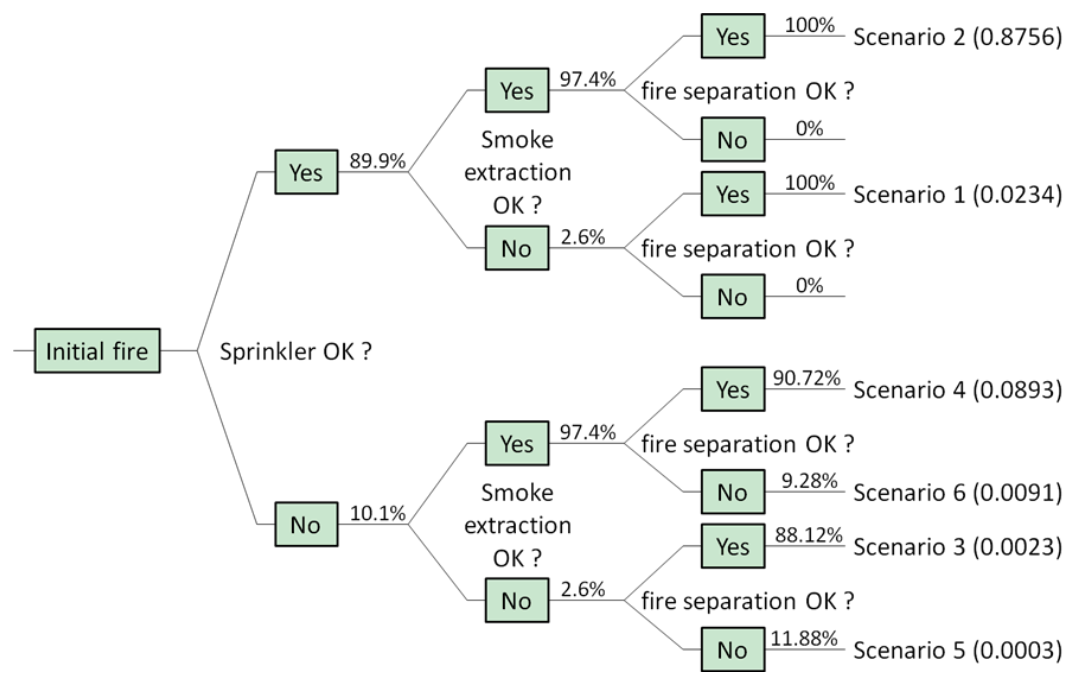

Fig. 4. Event tree for a fire development in the performance-based designed storage.

In this paper, the heat release rate of a design fire in its growing phase was simplified by using a t-squared fire curve, $\alpha t^{2}$. The fire growth rate can be classified into fast according to the property of the combustibles, $\alpha=0.047 \mathrm{~kW} / \mathrm{s}^{2}$. The effect of the sprinkler system was modeled by a constant heat release rate from the time of activation [17] that was calculated using DETACT-T2 [18] from NIST. The fire source was simplified conservatively located at the floor, i.e., $13.5 \mathrm{~m}$ below the sprinklers. If the sprinkler system is effective, the estimated sprinkler activation times are 6.00 and $5.72 \mathrm{~min}$ for the prescriptive and performance-based designs respectively. The corresponding constant maximum heat release rates are 6.1 MW and 5.5 MW respectively. The difference is due to the different RTI-values. If the sprinkler system is ineffective and the fire separation zone is effective, the maximum heat release rate of the fire will be 129.6 MW when an entire stacking is ignited. If both the sprinkler system and fire separation zone are ineffective, the constant maximum heat release rate will be $225 \mathrm{MW}$ and $437 \mathrm{MW}$ for prescriptive and performancebased design storage respectively. This difference is due to different numbers of refrigerators therein. Six fire scenarios have been designed to describe the probable scenarios as summarized in Table 2. For the virtual prescriptive design storage, fire Scenarios 3 and 4 no longer exist because fire separation would be ineffective if the sprinkler system fails. And the probabilities of Scenario 5 and Scenario 6 are 0.0026 and 0.0984 respectively.

The above maximum heat release rates for scenarios are described below:

- Scenarios 1 and 2 of performance-based: ambient temperature $20{ }^{\circ} \mathrm{C}, \mathrm{RTI}=36 \sqrt{\mathrm{ms}}$, activation temperature $74{ }^{\circ} \mathrm{C}$, ceiling height was set at $13.5 \mathrm{~m}$ as the highest point of the roof for conservatism, detector spacing $3 \mathrm{~m}$. The result of activation time was $5.72 \mathrm{~min}$ with the maximum heat release rate of 5.5 MW for a fast fire growth rate.

- Scenarios 1 and 2 of the prescriptive design: RTI $=80 \sqrt{m s}$ with other parameters the same as in the performance-based. The result of activation time was $6 \mathrm{~min}$ with the maximum heat release rate of 6.1 MW for a fast fire growth rate. 
- Scenarios 3 and 4 of the performance-based design: a group of 9 refrigerators stacked as three stories was considered to be ignited together at first, and the fire to spread to its adjacent groups laterally with a time delay. The heat release rate curves for these scenarios were obtained by summing the ignited groups in each time period with the maximum value of $129.6 \mathrm{MW}$. The heat release rate curves were simplified as t-squared fast fires which are conservative choices.

- Scenarios 5 and 6 of the performance-based and prescriptive designs: the maximum heat release rates were estimated by multiplying the fire area expansion proportion by the maximum HRR of one stacking area. The maximum HRR of the performance-based and prescriptive storages were 437 and $225 \mathrm{MW}$ respectively. Here these scenarios were also simplified conservatively as t-squared fast fires.

Table 2. Six design fire scenarios and their constant maximum heat release rates.

\begin{tabular}{|c|c|c|c|c|c|c|c|}
\hline $\begin{array}{c}\text { Fire } \\
\text { scenario }\end{array}$ & $\begin{array}{l}\text { Sprinkler } \\
\text { system }\end{array}$ & $\begin{array}{c}\text { Smoke } \\
\text { extraction } \\
\text { system }\end{array}$ & $\begin{array}{c}\text { Fire } \\
\text { separation } \\
\text { zone }\end{array}$ & \multicolumn{2}{|c|}{$\begin{array}{l}\text { Performance- } \\
\text { based storage } \\
\text { (Probability) }\end{array}$} & \multicolumn{2}{|c|}{$\begin{array}{l}\text { Prescriptive } \\
\text { storage }\end{array}$} \\
\hline 1 & $\sqrt{ }$ & $x$ & $\sqrt{ }$ & \multirow{2}{*}{$\begin{array}{l}5.5 \\
\text { MW }\end{array}$} & 0.0234 & \multirow{2}{*}{$\begin{array}{l}6.1 \\
\text { MW }\end{array}$} & \multirow{2}{*}{$\begin{array}{l}0.0234 \\
0.8756 \\
\end{array}$} \\
\hline 2 & $\sqrt{ }$ & $\sqrt{ }$ & $\sqrt{ }$ & & 0.8756 & & \\
\hline 3 & $x$ & $x$ & $\sqrt{ }$ & \multirow{2}{*}{$\begin{array}{l}129.6 \\
\text { MW }\end{array}$} & 0.0023 & \multirow{2}{*}{\multicolumn{2}{|c|}{ I }} \\
\hline 4 & $\bar{x}$ & $\sqrt{ }$ & $\sqrt{ }$ & & 0.0893 & & \\
\hline 5 & $x$ & $x$ & $x$ & \multirow{2}{*}{$\begin{array}{c}437 \\
\text { MW }\end{array}$} & 0.0003 & \multirow{2}{*}{$\begin{array}{c}225 \\
\text { MW }\end{array}$} & 0.0026 \\
\hline 6 & $x$ & $\sqrt{ }$ & $x$ & & 0.0091 & & 0.0984 \\
\hline
\end{tabular}

“ $\sqrt{ }$ " represents effective; " $X$ " represents ineffective.

\section{RESULTS AND DISCUSSION}

ASET and RSET were quantitatively evaluated for the current performance-based design storage, as shown in Table 3. As for Scenarios 3 and 5, visibility was the first parameter that reached its risk threshold for both scenarios and ASETs were $626 \mathrm{~s}$ and $342 \mathrm{~s}$, respectively.

Infrared correlation smoke detector is used as the detection system in this storage, so its alarm time can be chosen as $120 \mathrm{~s}$ [19]. An estimate of time used for reaction and decision is $60 \mathrm{~s}$ as workers in the storage area are awake and familiar with the evacuation path according to categories in [19]. The time used for movement can be estimated as the value of evacuation distance divided by traveling speed as the storage is sparsely populated. The farthest evacuation distance is 60 meters, so movement time will be $60 \mathrm{~s}$ as traveling speed was assumed to be $1 \mathrm{~m} / \mathrm{s}$.

Having compared ASETs with RSETs, we found that workers in the current storage would evacuate safely in Scenarios 3 and 5. The ASETs for Scenarios 4 and 6 will be greater than $626 \mathrm{~s}$ and $342 \mathrm{~s}$, respectively, as the smoke extraction system is effective therein. Besides, the evacuation safety will be ensured in Scenarios 1 and 2 because initial fires can be suppressed in those two scenarios.

Table 3. Evacuation analysis.

\begin{tabular}{|l|c|c|c|}
\hline Fire scenario & RSET (s) & ASET (s) & Conclusion \\
\hline 3 & 252 & 626 & Safe \\
\hline 5 & 252 & 342 & Safe \\
\hline
\end{tabular}

In order to verify the second target, the smoke layer height, smoke layer temperature, and radiation intensity at 6 meters high were calculated using the Fire Dynamics Simulator (FDS) [16] from NIST. This software package has undergone some validations for its temperature and radiation heat transfer prediction capabilities [20]. However, it is noted that the effects of sprinkler activation on smoke layer height are not simulated in FDS though the effect on the heat release rates of fires are. So the results might not display the situations in real fires accurately. Scenario 1 has been used as an example of the comparison of fire intensity parameters between prescriptive and performance-based designed storages. Scenario 1 represents the fire development with effective sprinkler, ineffective smoke extraction, and effective fire separation 
zone. Fig. 5 (a) shows the time curves of smoke layer height from which we can see that both of them are higher than the critical safety height. The smoke layer heights of the prescriptive and performance-based design stabilize at about $5.0 \mathrm{~m}$ and $7.4 \mathrm{~m}$ respectively. From Fig. 5 (b) the smoke layer temperatures of these two storages are found to be far below their critical values. The steady temperature values of the prescriptive and performance-based designs are $86.5{ }^{\circ} \mathrm{C}$ and $48.2{ }^{\circ} \mathrm{C}$ respectively. Finally, the radiation intensities at 6 meters high are shown in Fig. 5 (c). The stable results of the prescriptive and performancebased are also far below their critical value as the former is $1.52 \mathrm{~kW} / \mathrm{m}^{2}$ and the latter is $0.75 \mathrm{~kW} / \mathrm{m}^{2}$. From the above, it can be concluded that the safety level of the performance-based design storage is not lower than that of the prescriptive for Scenario 1.

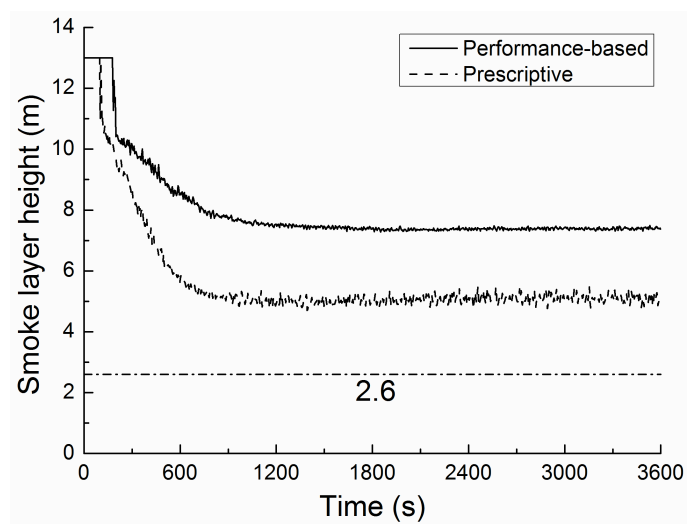

(a) Smoke layer height

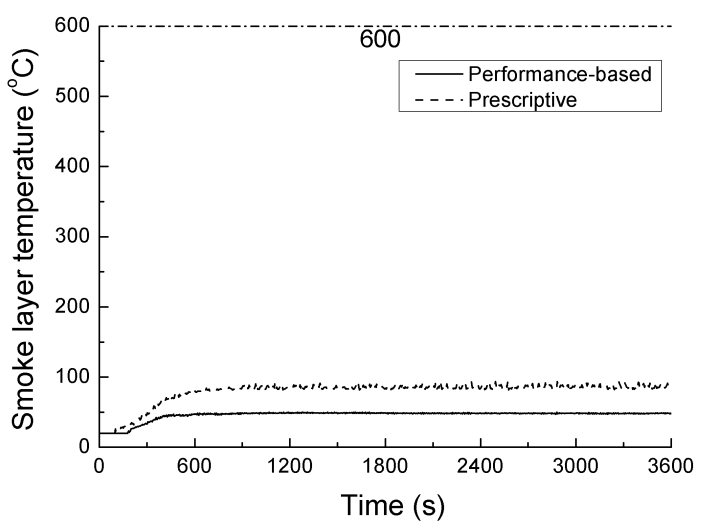

(b) Smoke layer temperature

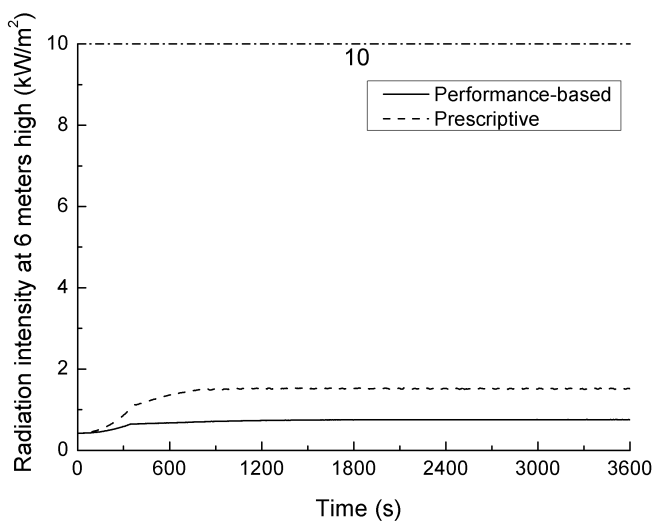

(c) Radiation intensities at 6 meters high

Fig. 5. Fire severity comparison of Scenario 1. 
The stable values of smoke layer height, smoke layer temperature, and radiation intensity for other scenarios are shown in Table 4. From this table the safety levels of the performance-based design storage were also found no lower than those of the prescriptive for Scenarios 2, 3, and 4. For Scenarios 5 and 6, all of the refrigerator stackings in the building will be ignited if the fire separation zone is ineffective. So in these two scenarios the risk of property loss of the performance-based storage will be far greater than that of prescriptive.

Table 4. Fire severity comparison for all scenarios.

\begin{tabular}{|c|c|c|c|c|c|}
\hline $\begin{array}{c}\text { Fire } \\
\text { scenario }\end{array}$ & Storage & $\begin{array}{c}\text { Smoke layer } \\
\text { height } \\
\text { (m) }\end{array}$ & $\begin{array}{c}\text { Smoke layer } \\
\text { temperature } \\
\left({ }^{\circ} \mathrm{C}\right)\end{array}$ & $\begin{array}{c}\text { Radiation } \\
\text { intensity at } \\
6 \text { meters high } \\
\left(\mathrm{kW} / \mathrm{m}^{2}\right)\end{array}$ & Conclusion \\
\hline \multirow{2}{*}{1} & Performance-based & 7.4 & 48.2 & 0.75 & \multirow{8}{*}{$\begin{array}{l}\text { The safety level of } \\
\text { performance-based } \\
\text { storage is not lower } \\
\text { than that of } \\
\text { prescriptive }\end{array}$} \\
\hline & Prescriptive & 5.0 & 86.5 & 1.52 & \\
\hline \multirow{2}{*}{2} & Performance-based & 7.3 & 48.4 & 0.76 & \\
\hline & Prescriptive & 6.9 & 78.0 & 1.29 & \\
\hline \multirow{2}{*}{3} & Performance-based & 6.1 & 188.0 & 3.45 & \\
\hline & Prescriptive & 1.9 & 265.5 & 5.45 & \\
\hline \multirow{2}{*}{4} & Performance-based & 6.5 & 229.9 & 3.99 & \\
\hline & Prescriptive & 2.0 & 269.3 & 5.65 & \\
\hline \multirow{2}{*}{5} & Performance-based & \multirow{4}{*}{\multicolumn{3}{|c|}{ All refrigerator stackings will be ignited }} & \multirow{4}{*}{$\begin{array}{l}\text { Risk of property } \\
\text { loss of } \\
\text { performance-based } \\
\text { storage will be far } \\
\text { greater than that of } \\
\text { prescriptive }\end{array}$} \\
\hline & Prescriptive & & & & \\
\hline \multirow[b]{2}{*}{6} & Performance-based & & & & \\
\hline & Prescriptive & & & & \\
\hline
\end{tabular}

After the comparison of the safety levels between the performance-based and prescriptive storages, the risk of property loss will be compared. A total of about 15000 refrigerators can be piled up in the performancebased storage with 2500 refrigerators in each stacking. If the early suppression fast response sprinkler system is effective (Scenarios 1 and 2), the expected damaged refrigerators by the initial fire will be 31 (refrigerators ignited before ESFR sprinkler activated); if the sprinkler system is ineffective and the fire separation zone is effective (Scenarios 3 and 4), the expected damaged refrigerators after fire spread in a stacking will be 2500; if the sprinkler system and fire separation zone are both ineffective (Scenarios 5 and 6), the expected damaged refrigerators after fire spread in all stackings will be 15000 .

A total of about 3750 refrigerators can be piled up in the prescriptive storage as its building area is a quarter of the performance-based storage and their stacking layouts are similar. If the standard sprinkler system is effective, the expected damaged refrigerators by the initial fire will be 34 (refrigerators ignited before standard sprinkler activated); if the sprinkler system is ineffective, fire will spread in all stackings and the expected damaged refrigerators will be 3750 . Comparing the expected damaged refrigerator numbers in Table 5, we can conclude that the risk of property losses between the performance-based and the prescriptive design storages are nearly equal.

Table 5. Expected fire loss.

\begin{tabular}{|c|c|c|c|c|}
\hline \multirow[b]{2}{*}{ Storage } & \multicolumn{3}{|c|}{ Expected damaged refrigerator number (probability) } & \multirow[b]{2}{*}{ Summation } \\
\hline & $\begin{array}{l}\text { Initial suppressed } \\
\text { fire }\end{array}$ & $\begin{array}{l}\text { One stacking } \\
\text { ignited }\end{array}$ & $\begin{array}{l}\text { All stacking } \\
\text { ignited }\end{array}$ & \\
\hline $\begin{array}{l}\text { Performance- } \\
\text { based }\end{array}$ & $31(0.899)$ & $2500(0.0916)$ & $15000(0.0094)$ & 398 \\
\hline Prescriptive & $34(0.899)$ & 1 & $3750(0.101)$ & 409 \\
\hline
\end{tabular}




\section{CONCLUSION}

The main objective of this paper was to demonstrate through a case study the implementation of the design philosophy "the safety level of a performance-based designed building should not be lower than that of a prescriptive". The safety level can be measured by either risk to life or expected fire loss or both. In terms of the latter two, the design philosophy can be expressed as "the risk to life and the expected fire loss of a performance-based building design should not be greater than that of prescriptive design". This statement also implies that the prescriptive code requirements and the associated risk are used as benchmark for fire safety engineering assessment. This approach resolves the issue of setting the quantifiable performance criteria for fire safety engineering design and assessment.

A large refrigerator storage warehouse was selected for the case study. The performance-based design, or the alternative solution adopted the removal of the fire rated partitions which are required by the prescriptive code. An early suppression fast response sprinkler system, fire separation zones, and retardant coating of the steel elements were also adopted to countervail the increased fire risk caused by the enlarged space. A virtual prescriptive code compliant storage warehouse was used for comparison. An event tree analysis was conducted to establish multiple fire scenarios and the associated probabilities. For each individual scenario, the deterministic timeline analysis was employed to assess occupant evacuation safety. The fire loss was measured in terms of the number of damaged refrigerators.

The result of the analysis revealed that the risk associated with performance-based design was less than that associated with the prescriptive code compliant design. It was also revealed that the widened transport passage was an essential feature of the alternative solution in order to minimize the loss of property, or building contents. The benefit of the widened passage was also reflected in the improvements in access and turnover.

In the fire loss or fire cost assessment, the current study did not include the cost of initial investment and the benefit of the widened transport passage. A full cost-benefit analysis would be desirable for decision making. The outcome of an absolute risk based fire engineering assessment will depend on the probability or reliability data of various fire protection devices. Uncertainty or variability exists in these input data. Even though the impact of this uncertainty on the outcome of two design solutions may be the same or similar because the same assessment approach is used, it may be necessary to conduct a sensitivity analysis such that it can be demonstrated that the performance-based design is capable of tolerating some extent of uncertainty in the reliability of the fire protection devices. The above highlighted issues will be the topics for future studies.

\section{ACKNOWLEDGEMENTS}

This research was supported by the Fundamental Research Funds for the Central Universities (WK2320000012).

\section{REFERENCES}

[1] Hadjisophocleous, G.V. and Benichou, N., (1999) Performance criteria used in fire safety design, Automation in Construction 8: 489-501, http://dx.doi.org/10.1016/S0926-5805(98)00096-X

[2] Meacham, B., Bowen, R., Traw, J., and Moore, A., (2005) Performance-based building regulation: current situation and future needs, Building Research \& Information 33: 91-106, http://dx.doi.org/10.1080/0961321042000322780

[3] Croce, P.A., Grosshandler, W.L., Bukowski, R.W., and Gritzo, L.A., (2008) The International FORUM of Fire Research Directors - A position paper on performance-based design for fire code applications, Fire Safety Journal 43: 234-236, http://dx.doi.org/10.1016/j.firesaf.2007.12.004

[4] He, Y. and Grubits, S., (2010) A Risk-based Equivalence Approach to Fire Resistance Design for Buildings, Journal of Fire Protection Engineering 20: 5-26, http://dx.doi.org/10.1177/1042391509360306

[5] "Code of Design on Building Fire Protection and Prevention GB 50016-2006," Ministry of Construction of the People's Republic of China, 2006. 
[6] Meacham, B.J., (2004) Understanding Risk: Quantification, Perceptions, and Characterization, Journal of Fire Protection Engineering 14: 199-227, http://dx.doi.org/10.1177/1042391504042454

[7] Nelson, H.E. and Mowrer, F.W., "Emergency Movement," The SFPE Handbook of Fire Protection Engineering ( $3^{\text {rd }}$ ed), DiNenno, P.J. (ed.), National Fire Protection Association, Quincy, MA 02269, 2002, p. 3/367.

[8] "International Fire Engineering Guidelines," Australian Building Codes Board, 2005.

[9] ISO/TR-13387, Fire Safety Engineering," International Standards Organisation, 1999.

[10] Hurley, M.J. and Rosenbaum, E.R., "Performance-Based Design," The SFPE Handbook of Fire Protection Engineering ( $4^{\text {th }} e d$ ), DiNenno, P.J. (ed.), National Fire Protection Association, Quincy, MA 02269, 2008, p. 3/440-3/455.

[11] Zhang, J.Q., Lu, S.X., Yuan, M., Li, C.H., and Li, Q., (2011) Safe Separation Distance Calculation Model with Changing Area of Fuel Packages in Large Space, Procedia Engineering 11: 666-674, http://dx.doi.org/10.1016/j.proeng.2011.04.711

[12] "NFPA 5000 Building Construction and Safety Code, 2006 edition," National Fire Protection Association, Quincy, MA 02169, 2006.

[13] "Code of design for sprinkler systems GB 50084-2001," Ministry of Construction of the People's Republic of China, 2001.

[14] Fan, W.C., Sun, J.H., and Lu, S.X., Fire risk assessment methodology, Science Press, Beijing, China, 2004, p. 272.

[15] Bukowski, R.W., Budnick, E.K., and Schemel, C.F., "Estimates of the Operational Reliability of Fire Protection Systems," Proceedings of the Third International Conference on Fire Research and Engineering, Chicago, USA, 1999, pp. 87-98.

[16] McGrattan, K., Klein B., Hostikka, S. and Floyd J., "Fire Dynamics Simulator (Version 5) User's Guide," National Institute of Standards and Technology Report NIST Special Publication 1019-5, Washington, USA, 2009.

[17] Evans, D. and Stroup, D., (1986) Methods to calculate the response time of heat and smoke detectors installed below large unobstructed ceilings, Fire Technology 22: 54-65, http://dx.doi.org/10.1007/bf01040244

[18] "Fire Modeling Software," National Institute of Standards and Technology, 2001.

[19] Fleischmann, C.M., "Prescribing the Input for the ASET versus RSET Analysis: Is This the Way Forward for Performance Based Design?," Fire Protection and Life Safety in Building and Transportation Systems, Santander, Spain, 2009, pp. 1-17.

[20] Mell, W., Maranghides, A., Mcdermott, R., and Manzello, S.L., (2009) Numerical simulation and experiments of burning douglas fir trees, Combustion and Flame 156: 2023-2041, http://dx.doi.org/10.1016/j.combustflame.2009.06.015 